\title{
LETTERS
}

\section{Safely restarting renal transplant programs should be a priority}

Many transplant centres have temporarily shut down their living donor kidney transplant programs "to ease pressure on hospitals and protect donors and recipients from coronavirus disease 2019 (COVID19)." ${ }^{1}$ These actions make sense. At the same time, pre-emptive renal transplantation with a living donor remains the optimal therapy for end-stage renal disease. ${ }^{2}$ Without this being an available therapeutic option, patients are being exposed to more dialysis and its associated risks (including increased risk of COVID-19). For example, according to registry data from France, the COVID-19 mortality rate was $30 \%$ among patients waitlisted for hemodialysis, compared with $13 \%$ in the kidney transplant population. ${ }^{3}$ As of May 6, 2020, the European Renal AssociationEuropean Dialysis and Transplant Association (ERA-EDTA) COVID-19 database has reported mortality rates of $20 \%$ and $18 \%$ for dialysis and kidney transplant patients, respectively. ${ }^{4}$

Given these data, workup of living donors must continue. Yet, strategies that minimize visits to hospital, address donor COVID-19-related anxiety and provide proper follow-up are essential. How can this be achieved?

First, in-person donor evaluations should take place in dedicated "cold zones" of the hospital. Testing must also be condensed (if possible) into a period of 1-2 days so that repeated trips to the hospital can be minimized. In addition, the perioperative period is generally a stressful time for the living donor. In the era of severe acute respiratory syndrome coronavirus 2 (SARS-Cov-2), this anxiety is likely to be increased. Mandatory SARS-CoV-2 testing, a 14-day self-quarantine period before the nephrectomy and hospital admission in a COVID-19-free zone will all be the "new normal." Lastly, given that historytaking, blood pressure measurement and laboratories encompass the bulk of living donor surveillance, most long-term followup can effectively be done on a virtual basis rather than in person.

For those living donors who are either $A B O$ or human leukocyte antigen incompatible with their recipient, paired exchange programs have provided excellent opportunities to proceed with transplantation. In Canada's kidney paired donation program, living donors have traditionally travelled to the recipient's transplant centre (often in a different province). Donor travel, particularly to a different province, can be a source of apprehension and a reason for refusal to participate (owing to perceived expense or lack of familiarity with the city or language, or both). With the emergence of COVID-19, donors can now add another reason to refuse participation. Given the above, transplant programs in Canada should adopt ways to efficiently ship kidneys (while minimizing cold ischemic time and delayed graft function). ${ }^{5}$

In summary, as both a life-saving and cost-effective therapy, hospitals and health care systems must strive to return to safely performing living donor kidney transplantation. With donor anxiety and stress further inflamed by COVID-19, measures that financially and medically protect the living donor are more important than ever before.

\section{Daniel Fantus MSc MD}

Transplant nephrologist, Department of Medicine, Centre Hospitalier de l'Université de Montréal (CHUM) and Centre de Recherche de CHUM (CRCHUM), Montréal, Que.

\section{Michel R. Pâquet MD PhD}

Transplant nephrologist, Department of Medicine, Centre Hospitalier de l'Université de Montréal (CHUM), Montréal, Que.

- Cite as: CMAJ 2020 August 24;192:E988. doi: $10.1503 / \mathrm{cmaj} .76277$

\section{References}

1. Owens B. Organ transplants drop dramatically during pandemic. CMAJ 2020;192:E692-3.

2. Yoo SW, Kwon OJ, Kang CM. Preemptive livingdonor renal transplantation: outcome and clinical advantages. Transplant Proc 2009;41:117-20.

3. Reprise de l'activité de greffe rénale adulte en période épidémique de SARS-CoV-2 (Covid-19): recommandation des sociétés savantes (SFT/SFNDT/AFU). Paris: La Société Francophone de Transplantation; 2020. Available: www.transplantation-francophone. org/images/public/Reprise_de_lactivite_de_ transplantation_renale_adulte_argumentaire_SFT_ SFNDT.pdf (accessed 2020 May 14).

4. The ERA-EDTA COVID-19 database for patients on kidney replacement therapy. Parma (Italy): ERAEDTA; 2020. Available: www.era-edta.org (accessed 2020 May 20).

5. Segev DL. Innovative Strategies in living donor kidney transplantation. Nat Rev Nephrol 2012;8:332-8.

Competing interests: None declared. 